\title{
NGHIÊN CÚU XÂY DỰNG CÔNG CỰ HỖ TRỢ LẬP KẾ HOẠCH SỬ DỤNG ĐẤT HÀNG NẨM CẤP HUYỆN
}

\author{
HOÀNG TH! TÂM, NGUYẼ̃N TH!̣ CHI, NGUYẼ̃N TH!̣ THẢO \\ Viện Khoa học Đo đạc và Bản đồ
}

\section{Tóm tắt:}

Bài báo này giới thiệu kết quả nghiên cứu quy trình chuẩn hóa, chiết xuất, tổng hợp thông tin tì dũ liệu bản đồ hiện trạng sủ dụng đất, bản đồ kế hoạch sủ dụng đất trên co sở đó xây dụng công cu hỗ trọ thành lập các bảng, biểu số liệu phục vu công tác lập kế hoạch sử dụng đất hàng năm cấp huyện.

\section{1. Đặt vấn đề}

Theo quy định mới nhất của Luật đất đai năm 2013 và Nghị định 43/2014/NĐ-CP ngày $15 / 5 / 2014$ của Chính phủ thì kỳ kế hoạch sử dụng đất cấp quốc gia, cấp tỉnh và kỳ kế hoạch sử dụng đất quốc phòng, đất an ninh là 05 năm. Kỳ kế hoạch sử dụng cấp huyện được lập hàng năm. Như vậy, lập kế hoạch sử dụng đất hàng năm là việc làm thường xuyên của cấp huyện. Thông tư số 29/2014/TT-BTNMT ngày 02/6/2014 cũng đã quy định chi tiết việc lập, điều chỉnh quy hoạch, kế hoạch sử dụng đất. Tuy nhiên, cho đến nay công tác lập kế hoạch sử dụng đất hàng năm ở các địa phương vẫn còn nhiều bất cập. Dưới đây trình bày kết quả nghiên cứu xây dựng công cụ hỗ trợ thành lập các bảng, biểu số liệu phục vụ công tác lập kế hoạch sử dụng đất thực hiện trong khuôn khổ đề tài nghiên cứu khoa hoc và công nghệ "Nghiên cứu xây dựng phần mềm hỗ trợ lập kế hoạch sử dụng đất cấp huyện"

\section{Dữ liệu và phương pháp nghiên cứu}

- Phương pháp điều tra số liệu thứ cấp: Các tài liệu, số liệu, bản đồ được điều tra, thu thập tại phòng Tài nguyên và Môi trường huyện Kim Động, tỉnh Hưng Yên. Dữ liệu thực nghiệm được thu thập và chuẩn hóa gồm bản đồ hiện trạng sử dụng đất, bản đồ quy hoạch sử dụng đất cuối kỳ của các xã trên địa bàn huyện Kim Động, tỉnh Hưng Yên, chỉ tiêu quy hoạch sử dụng đất của huyện được cấp trên giao.
- Phương pháp thực nghiệm mô hình: để thành lập các bảng biểu phục cụ công tác lập kế hoạch sử dụng đất cấp huyện tại nghiên cứu này, chúng tôi giới thiệu phương pháp trên cơ sở nghiên cứu mô hình lý thuyết và đã tiến hành thử nghiệm tại huyện Kim Động, tỉnh Hưng Yên.

3. Quy trình thành lập các bảng, biểu phục vụ công tác lập kế hoạch sử dụng đất hàng năm cấp huyện

Quy trình thành lập các bảng biểu phục vụ công tác lập kế hoạch sử dụng đất hàng năm cấp huyện gồm 4 bước (Hình 1). Theo đó, các bảng, biểu kế hoạch sử dụng đất được tự động xuất ra từ cơ sở dữ liệu quy hoạch, kế hoạch sử dụng đất trên cơ sở tổng hợp, chiết xuất thông tin từ bản đồ hiện trạng sử dụng đất (sau khi đã được cập nhật và chuẩn hóa) và chỉ tiêu quy hoạch sử dụng đất cho năm kế hoạch. (Xem hình 1)

\subsection{Thu thập thông tin, dũ liệu đầu vào}

Dữ liệu cần thu thập để phục vụ cho việc tính toán bảng, biểu số liệu kế hoạch sử dụng đất hàng năm cấp huyện bao gồm:

- Số liệu QHSDĐ cuối kỳ của huyện, số liệu KHSDĐ 5 năm kỳ đầu;

- Bản đồ QHSDĐ cuối kỳ của huyện;

- Bản đồ HTSDĐ và báo cáo KHSDĐ năm trước của huyện;

- Chỉ tiêu sử dụng đất cho năm kế hoạch;

- Bản đồ kế hoạch sử dụng đất năm kế hoạch.

Ngày nhận bài: 11/6/2018, ngày chuyển phản biện: 12/6/2018, ngày chấp nhận phản biện: 20/6/2018, ngày chấp nhận đăng: 21/6/2018 
Bước 1: Thu thập thông tin, dữ liệu đầu vào

Bước 2: Nhập và chuẩn hóa dữ liệu hiện trạng, kế hoạch sử dụng đất

Bước 3: Tích hợp cơ sở dữ liệu kế hoach sỉ̛ dung đất

Bước 4: Tổng hợp các bảng biểu KHSDĐ (PL03-TT29-BTNMT)

Hình 1: Quy trình thưc hiện thành lập các bảng, biểu kế hoạch sự dụng đất

\subsection{Nhập và chuẩn hóa dĩ liệu hiện trạng, dũ liệu kế hoạch sử dụng đất.}

Để có bộ số liệu thống kê đất đai hàng năm đầy đủ, chính xác phục vụ công tác lập kế hoạch sử dụng đất cấp huyện, các đối tượng trên bản đồ hiện trạng sử dụng đất phải được chuẩn hóa về phân lớp, màu sắc, lực nét và các thông số đúng theo quy định tại Thông tư số 28/2014/TTBTNMT ngày $2 / 6 / 2014$. Công cụ nhập và chuẩn hóa dữ liệu được tiến hành xây dựng nhằm mục đích hỗ trợ người dùng trong việc chuẩn hóa, tạo vùng và gán thông tin thuộc tính là lớp Địa giới và lớp Ranh giới thửa đất.

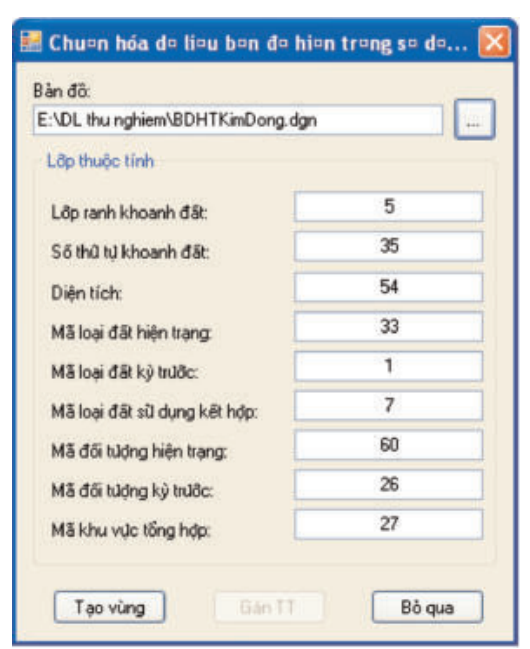

Hình 2: Giao diện công cu Nhập và chuẩn hóa dũ liệu hiện trạng

\subsection{Tích hợp cơ sở dũ liệu kế hoạch sủ dụng đất}

Với dữ liệu Địa giới, dữ liệu Hiện trạng, dữ liệu Quy hoạch đã được chuẩn hóa, thực hiện tích hợp 3 lớp dữ liệu để tạo thành CSDL kế hoạch sử dụng đất, phục vụ cho việc tự động tạo hệ thống các bảng biểu kế hoạch theo TT29BTNMT.

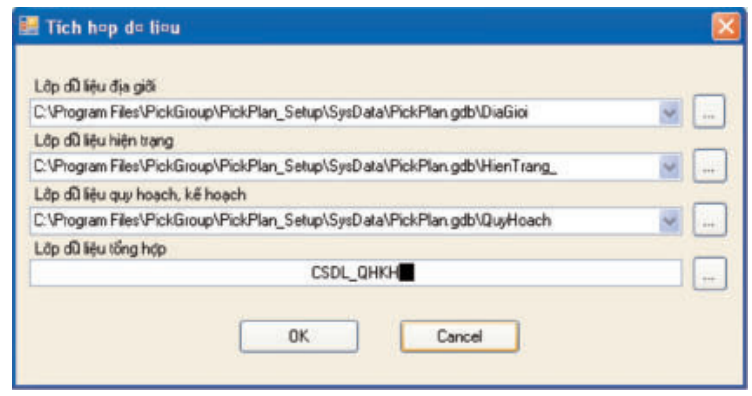

Hình 3: Công cu tích hơp dũ liệu kế hoạch sư dụng đất

\subsection{Tổng hợp các bảng biểu kế hoạch sử dụng đất}

Hệ thống các mẫu biểu số liệu kế hoạch sử dụng đất hàng năm cấp huyện được quy định theo phụ lục 03 ban hành kèm thông tư 29/2014/TT- BTNMT[1]. Hệ thống bảng, biểu số liệu phục vụ công tác lập kế hoạch sử dụng đất được modul tự động tính toán theo hình 4 :

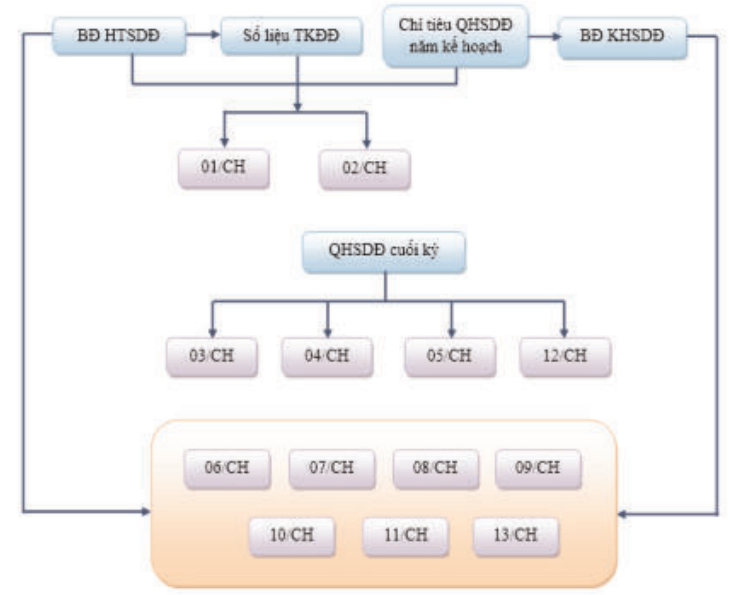

Hình 4: Trình tụ tính toán bảng biểu số liệu kế hoạch sử dụng đất 


\section{Kết quả}

Với mục đích hỗ trợ công tác lập kế hoạch sử dụng đất hàng năm cấp huyện theo quy định của Bộ Tài nguyên và Môi trường, modul tiện tích đã được xây dựng nhằm hỗ trợ tối đa trong việc tính toán số liệu, bảng biểu số liệu thống kê kế hoạch sử dụng đất dựa trên nền tảng công nghệ ArcGIS Engine và ngôn ngữ lập trình $\mathrm{C}$. Với nền tảng công nghệ ArcGIS Engine và ngôn ngữ lập trình C\#, modul hỗ trợ lập kế hoạch sử dụng đất cấp huyện sẽ được cung cấp bộ thư viện đầy đủ nhất về các thuật toán GIS cho phép modul được đóng gói chạy độc lập.

Modul được thiết kế theo mô hình hệ thống mở, sử dụng CSDL mô tả dữ liệu thuộc tính cho từng lớp đối tượng. Modul tiếp nhận các file bản đồ hiện trạng, quy hoạch sử dụng đất định dạng chuẩn *.dgn theo quy định của Bộ Tài nguyên và Môi trường. Các số liệu thống kê được tự động phân tích GIS từ đó thông qua thuật toán để mô hình hóa bằng ngôn ngữ đồ họa. Modul hoạt động trên hệ điều hành Windows, giao diện tiếng Việt.

Yêu cầu tối thiểu với hệ thống để cài đặt modul này:

Hệ điều hành: Windowns XP, Win 7, Win 10,

Bộ nhớ RAM: 1GB

Bộ vi xử lý CPU: 1.6Ghz, 533FSB

Ổ cứng còn trống dung lượng ít nhất là $500 \mathrm{M}$.

ArcGIS Engine 10.1 trở lên.

Dữ liệu đầu vào là bản đồ hiện trạng sử dụng đất, bản đồ kế hoạch sử dụng đất đã được chuẩn hóa, gán đủ thông tin. Hệ thống các bảng, biểu phục vụ công tác lập kế hoạch sử dụng đất cấp huyện, đảm bảo các yêu cầu tại Thông tư số 29/2014/TT-BTNMT. (Xem hinh 5)

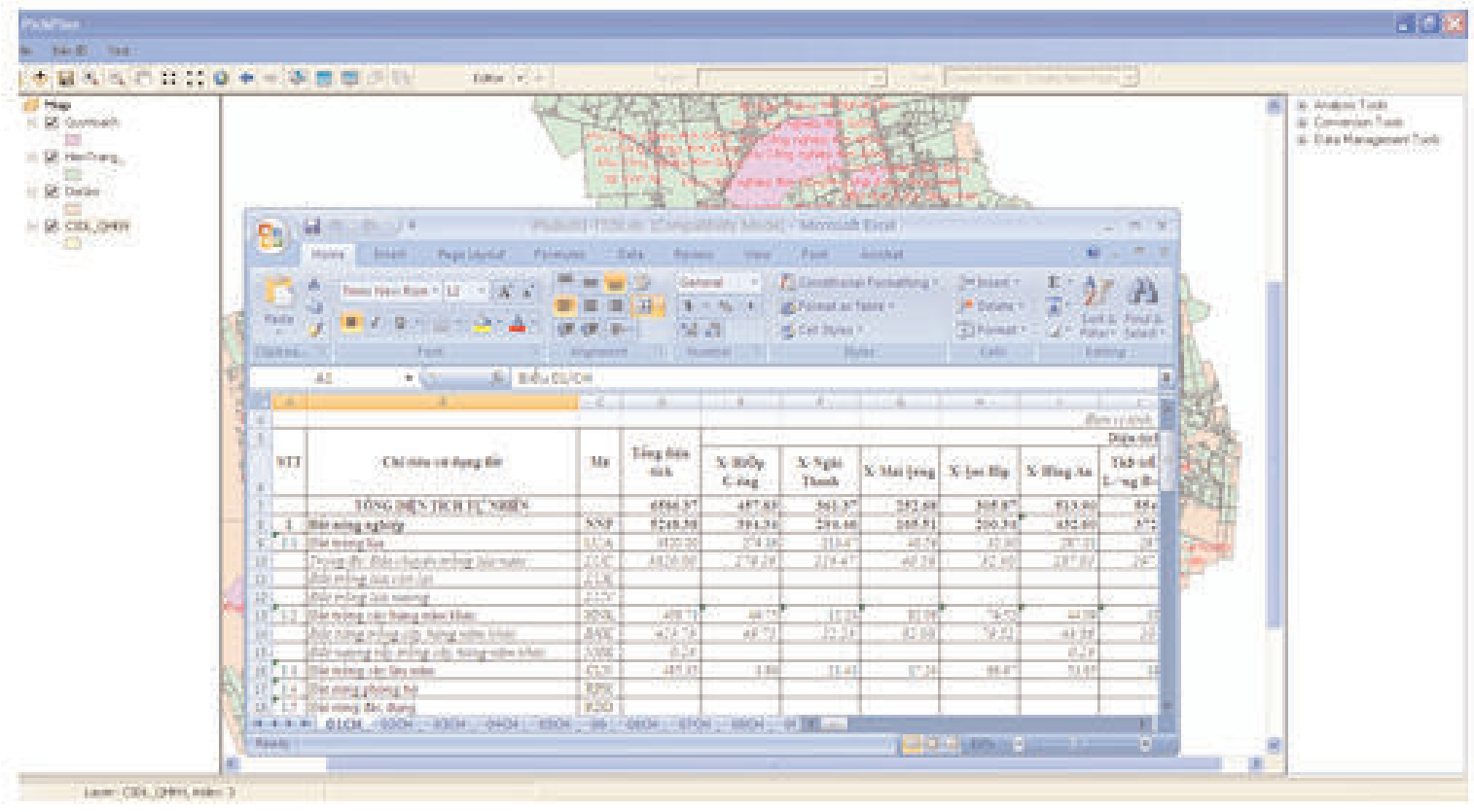

Hìn 6: Kết quả tạo bảng biểu số liệu kế hoạch sủ dụng đất 


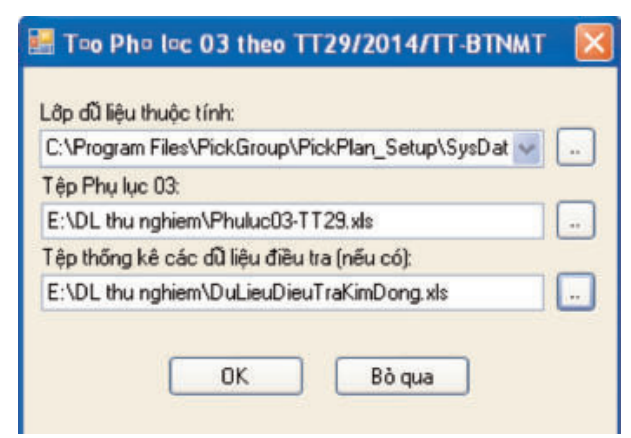

Hình 5: Giao diện công cu Tạo phụ lục 03

\section{Kết luận}

Kết quả nghiên cứu xây dựng công cụ hỗ trợ thành lập các bảng, biểu phục vụ công tác lập kế hoạch sử dụng đất cấp huyện theo Thông tư 29/2014/TT-BTNMT hoàn toàn được tổng hợp và chiết xuất thông tin từ cơ sở dữ liệu kế hoạch sử dụng đất. Kết quả đảm bảo sự liên thông, kết nối giữa dữ liệu không gian và thuộc tính, qua đó khắc phục được những bất cập trong công tác lập kế hoạch sử dụng đất cấp huyện ở các địa phương.
Kết quả thực nghiệm modul trong công tác lập kế hoạch sử dụng đất cấp huyện năm 2017 ở huyện Kim Động, tỉnh Hưng Yên đã đáp ứng tốt các yêu cầu theo quy định của Bộ Tài nguyên và Môi trường và có thể áp dụng modul này trong công tác lập kế hoạch sử dụng đất hàng năm cấp huyện. $O$

\section{Tài liệu tham khảo}

[1]. Bộ Tài nguyên và Môi trường (2014). Thông tư số 29/TT-BTNMT ngày 2/6/2014 của Bộ Tài nguyên và Môi trường quy định chi tiết việc lập, điều chỉnh quy hoạch, kế hoạch sử dụng đất.

[2]. Chính phủ (2014). Nghị định số 43/2014/NĐ-CP ngày 15/5/2014 của Chính phủ quy định chi tiết thi hành một số điều của Luật Đất đai.

[3]. Quốc hội nước Cộng hòa xã hội chủ nghĩa Việt Nam (2013). Luật số 45/2013/QH13: Luật Đất đai.O

\section{Summary}

\section{Building tools for annual land-use planning at the district level}

\section{Hoang Thi Tam, Nguyen Thi Chi, Nguyen Thi Thao}

Vietnam Institute of Geodesy and Cartography

This article summarizes the processes of data extracting and synthetizing from land-use status and planning maps. The article also introduces the tools which support annual land-use data reporting and planning at the district level. $\bigcirc$ 